\title{
USE OF PROBIT ANALYSIS IN A STUDY OF THE EFFECT OF THE RAM ON TIME OF OVULATION IN THE EWE
}

\author{
S. D. PARSONS,* G. L. HUNTER* AND A. A. RAYNER $\dagger$ \\ *Department of Animal Science and $\dagger$ Department of Biometry, \\ University of Natal, Pietermaritzburg, South Africa
}

(Received 6th May 1966)

\begin{abstract}
Summary. To investigate the relationship between oestrus and time of ovulation from the start of heat and the effect of the ram on this relationship, 200 ewes, half of which had been run with rams continuously during oestrus, were slaughtered at intervals after the end of heat. The method of probit analysis was used to fit multiple regression equations for percentage of ewes ovulated (as a probit) in terms of slaughter time and heat length. From these equations, estimates of mean ovulation times for various heat lengths were calculated. In the control group, which was teased at 4-hr intervals to determine lengths of heat, ovulation occurred, on the average, shortly after the end of oestrus. Although duration of oestrus was shorter when the sexes were continuously associated, ovulation occurred later. In addition, there was a positive correlation between heat length and time of ovulation in this group, but not in the control group.
\end{abstract}

\section{INTRODUCTION}

Bischoff (1844) and Marshall (1904) observed that ovulation in the ewe is spontaneous and occurs after the onset of heat. It has since been reported that ovulation occurs either towards the end of oestrus (Quinlan \& Maré, 1931; Grant, 1934; Cole \& Miller, 1935) or shortly after the end of oestrus (Kelley, 1937; Anderson, 1938). McKenzie \& Terrill (1937) recorded ovulation occurring at times varying from $11 \mathrm{hr}$ before to $6 \mathrm{hr}$ after the end of oestrus. It was suggested by Quinlan \& Maré (1931) that termination of oestrus is dependent upon rupture of the follicle, and McKenzie \& Terrill (1937) found a positive correlation between length of heat and ovulation time, i.e. the interval from the commencement of oestrus to ovulation. Since mean duration of oestrus is reduced by 4 to $12 \mathrm{hr}$ by continuous association of the sexes during oestrus (Zeltobrjuh \& Rak, 1964; Parsons \& Hunter, 1967), the effect of such association on the time of ovulation is of interest and possibly of practical significance in sheep breeding. Zeltobrjuh \& Rak (1964) found that association of the sexes during oestrus led to earlier rupture of the follicle. On the other hand, Ivanow (1913) and McKenzie \& Terrill (1937) reported that coitus 
had no effect on time of ovulation. In addition, it has been shown that a minimum period of about $24 \mathrm{hr}$ generally elapses between the onset of heat and the rupture of the follicle (Ivanow, 1913; Allen, McKenzie, Kennedy \& Beare, 1931; Quinlan \& Maré, 1931), even if mean heat length is as short as $16 \mathrm{hr}$ (Anderson, 1938).

Previously, time of ovulation in the ewe has been determined by one of two techniques. More commonly, ewes have been autopsied, or laparotomized once, at various intervals after the onset of oestrus and a range of ovulation times determined for the population (Grant, 1934; Anderson, 1938; and others). In a modification of this approach, estimates of the time of ovulation have been made by examining the ovaries of each animal both before and after the expected time of ovulation (Zeltobrjuh \& Rak, 1964). In the latter case, the accuracy of the estimate depends upon there being a reasonably short interval between the observations and ovulation in each ewe. A second method used to determine time of ovulation has involved continuous observations of the ovaries of live, anaesthetized ewes (McKenzie \& Terrill, 1937). Since the follicle may rupture before the end of oestrus, it is necessary in both methods to commence observations of ovarian activity before oestrus terminates, with the result that duration of oestrus cannot be determined for all ewes. In this paper a method is described in which ovulation time was determined by a variation of the first method: all ewes were autopsied after the end of oestrus, but the statistical technique permitted the utilization of records of all animals to estimate mean ovulation time, irrespective of whether ovulation had occurred before or after the end of oestrus. The object of the experiment was to determine the effect on ovulation time of continuous association of the sexes during oestrus.

\section{MATERIALS AND METHODS}

The experiment was conducted between 19th March and 3rd April 1964, at the Ukulinga Experiment Station, Pietermaritzburg. A total of 232 mature Merino ewes (fifty-five of which were classed as 'old') was available. The ewes of each age group (mature and old) were evenly and randomly divided among two groups, each totalling 116 ewes. The sheep were housed in pens in groups of thirty, each with one Merino ram, and fed $2 \mathrm{lb}$ of lucerne hay per head daily and unlimited veld hay. The time of onset of oestrus in the first 100 ewes of each group was determined by constant observation for mating behaviour. As soon as they had been mated, these ewes were removed to the appropriate pens, where treated ewes remained with rams throughout oestrus and control ewes were joined by rams only for short periods of teasing to determine length of heat. Duration of oestrus in the ewes of both groups was determined by teasing at intervals of $4 \mathrm{hr}$ for the first $24 \mathrm{hr}$ of oestrus, and more frequently thereafter in order that end of heat might be determined as accurately as possible. At the estimated time of ovulation (to be discussed shortly), each ewe was stunned with a captive bolt and bled. Immediately thereafter the reproductive tract was removed and stored in a refrigerator. Once a day, the tracts collected during the preceding $24 \mathrm{hr}$ were transferred to the laboratory, where the ovaries were examined, using a dissecting microscope, and classified as either ovulated or not ovulated. 
Statistical methods

Because of the quantal nature of the observations (ovulated or not ovulated), estimates of the mean ovulation time for the two groups (measured from the beginning of oestrus) were obtained by the method of probit analysis (Finney, 1962). This technique has been used particularly in biological assays (for example, of insecticides), but it has also found a diversity of applications such as the estimation of the limina of separate items of a mental test (Finney, 1944) and the determination of mean age of menarche (Wilson \& Sutherland, 1950; Burrell, Healy \& Tanner, 1961). In a typical assay of two insecticides, for example, batches of insects are exposed to a range of doses of each poison and a linear relationship is usually postulated between percentage kill expressed as probit $(Y)$ and $\log$ dose $(x)$ according to the model:

$$
r=\alpha+\beta x \text {. }
$$

The estimation procedure consists of fitting weighted linear regression lines to the data for each poison and, for simplicity, these lines are generally made parallel. The adoption of parallel regression lines is equivalent to an assumption that the distributions of the tolerances of the insects (with respect to the two insecticides) have equal variances. Since the tolerance of an individual insect cannot be directly observed, the situation is similar to that of the present experiment, where direct determination of time of ovulation was impossible. In our application, therefore, $Y$ is the probit corresponding to the percentage of ewes ovulated, and $x$ is the time of slaughtering after onset of oestrus, which is never less than the duration of oestrus.

With ewes coming on heat at various times and having varying heat lengths, the arrangement into batches was impracticable. Accordingly, the methods propounded by Finney (1947a) for this situation were followed.

Since Finney (1962) stipulates that the $50 \%$ point, i.e. the mean ovulation time, must be bracketed 'at all costs', the procedure of allocating a slaughtering time for a particular ewe was to guess the time of ovulation of that ewe in the light of its observed heat length and of results from previous ewes, and to make this the slaughtering time. Errors in these guesses were relied upon to give a reasonable spread of slaughtering times about the mean ovulation time for a given heat length, and from the fitted equations this was apparently achieved. The percentages of ewes found to have ovulated at the end of the experiment were $41 \%$ in the treatment group and $63 \%$ in the control group.

In many biological assays it is usual to transform the dose, so that the distribution of tolerances will be normal and the true relationship between probit and dose linear. Since the possibility that the distribution of ovulation times might be skew could not be excluded, the necessity for transforming the slaughtering times was investigated in two ways: (1) in the preliminary process of fitting provisional regression lines by grouping the data, the untransformed data seemed to be reasonably linear, whereas the log transformation tended to give a curve; and (2) on the basis of the presumed positive correlation of heat length and time of ovulation, frequency distributions of heat lengths were drawn up for the two groups. These revealed no marked skewness, but did reveal an apparent bimodality in the case of the treatment group. A check made 
by drawing up separate frequency distributions for the two age groups among the sheep, showed that the bimodality could not be attributed to this. The most probable reason is a grouping effect due to the inaccurate determination of end of oestrus with 4-hr teasing intervals, but the possibility of some differential effect of the exposure to the ram cannot be excluded, even though there is no obvious way of accounting for such an effect.

In the model $r=\alpha+\beta x$ length of heat is ignored, whereas an important objective was to determine the relationship between length of heat and ovulation time. On the suggestion of D. J. Finney (personal communication) this objective was achieved by the introduction of heat length as a covariate. This is equivalent to fitting probit planes (Finney, 1943) to the data for the two groups, according to the model

$$
\left.\begin{array}{l}
Y_{\mathrm{t}}=\alpha_{\mathrm{t}}+\beta_{1 \mathrm{t}} x_{1}+\beta_{2 \mathrm{t}} x_{2} \\
Y_{\mathrm{c}}=\alpha_{\mathrm{c}}+\beta_{1 \mathrm{c}} x_{1}+\beta_{2 \mathrm{c}} x_{2}
\end{array}\right\}
$$

where $x_{1}$ is the slaughter time, $x_{2}$ is heat length, and the suffixes $\mathrm{t}$ and $\mathrm{c}$ indicate treatment and control respectively. The parameters of the model were also estimated under the hypothesis of parallelism $\left(\beta_{1 \mathrm{t}}=\beta_{1 \mathrm{c}}, \beta_{2 \mathrm{t}}=\beta_{2 \mathrm{c}}\right)$. In addition, the extended model

$$
\left.\begin{array}{l}
Y_{\mathrm{t}}=\alpha_{\mathrm{t}}+\beta_{1 \mathrm{t}} x_{1}+\beta_{2 \mathrm{t}} x_{2}+\beta_{3 \mathrm{t}} x_{1} x_{2} \\
Y_{\mathrm{c}}=\alpha_{\mathrm{c}}+\beta_{1 \mathrm{c}} x_{1}+\beta_{2 \mathrm{c}} x_{2}+\beta_{3 \mathrm{c}} x_{1} x_{2}
\end{array}\right\}
$$

was fitted, again with provision for testing a hypothesis of parallelism $\left(\beta_{1 \mathrm{t}}=\beta_{1 \mathrm{c}}\right.$, $\left.\beta_{2 \mathrm{t}}=\beta_{2 \mathrm{c}}, \beta_{3 \mathrm{t}}=\beta_{3 \mathrm{c}}\right)$. The fitted equations, which must be calculated by a process of iteration, have the general form:

$$
\begin{aligned}
\hat{Y} & =a+b_{1} x_{1}(\operatorname{model} 1) \\
\hat{Y} & =a+b_{1} x_{1}+b_{2} x_{2}(\text { model } 2) \\
\text { or } \hat{Y} & =a+b_{1} x_{1}+b_{2} x_{2}+b_{3} x_{1} x_{2} \text { (model 3). }
\end{aligned}
$$

The mean ovulation time ignoring heat length is estimated by $\hat{x}_{1}$, the value of $x_{1}$ for $Y=5$ in equation (4). The estimated mean ovulation time for a given heat length $\left(X_{2}\right)$ is found by putting $r=5$ and $x_{2}=X_{2}$ in equations (5) or (6). The theoretical percentage of ewes which should have ovulated by a given time $X_{1}$ (ignoring heat length) is found by putting $x_{1}=X_{1}$ in equation (4) or for a given heat length $\left(X_{2}\right)$ by putting $x_{1}=X_{1}$ and $x_{2}=X_{2}$ in equations (5) or (6); in each case the calculated probit $Y$ is transformed back to a percentage.

The variance of $\hat{x}_{1}$ using equation (6) is given approximately by the following formula derived in accordance with methods presented by Finney (1947b):

$$
\begin{aligned}
V\left(\hat{x}_{1}\right)= & \frac{1}{\left(b_{1}+b_{3} X_{2}\right)^{2}}\left\{\frac{1}{\Sigma w}+\left(\hat{x}_{1}-\bar{x}_{1}\right)^{2} c_{11}+\left(X_{2}-\bar{x}_{2}\right)^{2} c_{22}+\left(X_{2} \hat{x}_{1}-\bar{x}_{3}\right) c_{33}\right. \\
& +2\left(X_{2}-\bar{x}_{2}\right)\left(x_{1}-\bar{x}_{1}\right) c_{12}-2\left(\hat{x}_{1}-\bar{x}_{1}\right)\left(X_{2} \hat{x}_{1}-\bar{x}_{3}\right) c_{13} \\
& \left.+2\left(X_{2}-\bar{x}_{2}\right)\left(X_{2} \hat{x}_{1}-\bar{x}_{3}\right) c_{23}\right\}
\end{aligned}
$$


where $\Sigma w$ is the sum of the weights used in the last iteration of the fitting process, $\bar{x}_{1}, \bar{x}_{2}, \bar{x}_{3}$ are the weighted means of $x_{1}, x_{2}$ and $x_{1} x_{2}$, and $c_{i i}$ and $c_{i j}$ are the diagonal and non-diagonal elements of the variance-covariance matrix of $b_{1}$, $b_{2}$ and $b_{3}$. The variance of $\hat{x}_{1}$ when equation (5) is used is found by putting $b_{3}, c_{33}, c_{13}$ and $c_{23}$ all zero in equation (7) and is:

$$
V\left(\hat{x}_{1}\right)=\frac{1}{b_{1}^{2}}\left\{\frac{1}{\Sigma w}+\left(\hat{x}_{1}-\bar{x}_{1}\right)^{2} c_{11}-2\left(\hat{x}_{1}-\bar{x}_{1}\right)\left(X_{2}-\vec{x}_{2}\right) c_{12}+\left(X_{2}-\bar{x}_{2}\right)^{2} c_{22}\right\}
$$

However, the calculated values of $\Sigma w, c_{11}, c_{12}, c_{22}$ are not the same in equations (5) and (6). For $\hat{x}_{1}$ calculated from (4) the variance is:

$$
V\left(\hat{x}_{1}\right)=\frac{1}{b_{1}^{2}}\left\{\frac{1}{\Sigma w}+\frac{\left(\hat{x}_{1}-\tilde{x}_{1}\right)^{2}}{\Sigma w\left(x_{1}-\tilde{x}_{1}\right)^{2}}\right\}
$$

The above variances must be multiplied by a heterogeneity factor should the $\chi^{2}$ test for deviations from regression prove significant. Without batches of reasonable size the $\chi^{2}$ value calculated in the ordinary way is unreliable, since the theoretical requirements for the test are not met. However, in the absence of significance (as in the present experiment) there is probably no cause to suspect heterogeneity.

In the same way, the usual $\chi^{2}$ tests of validity are affected and consequently the following types of tests of significance were substituted:

(i) To test whether model (3) provides a significantly more precise description of the data than model (2), i.e. whether the interaction term $x_{1} x_{2}$ contributes significantly to the regression. Here the normal test $u=b_{3} / \sqrt{ } c_{33}$ is used, i.e. $u$ is tested as a standard normal variate. The addition of $x_{2}$ in model (2), as compared with model (1), may be similarly tested.

(ii) To test the hypothesis of parallelism. Any regression coefficient in the fitted equation of type (4), (5) or (6) for the treatment group may be compared with the corresponding regression coefficient in the equation of the same type for the control group. The normal test is again used; for example:

$$
u=\frac{b_{2 \mathrm{t}}-b_{2 \mathrm{c}}}{\sqrt{ }\left(c_{22 \mathrm{t}}+c_{22 \mathrm{c}}\right)}
$$

where $c_{22 \mathrm{t}}$ and $c_{22 \mathrm{c}}$ are the variances of $b_{2 \mathrm{t}}$ and $b_{2 \mathrm{c}}$, estimates of $\beta_{2 \mathrm{t}}$ and $\beta_{2 \mathrm{c}}$ respectively.

In addition, since the variances (7), (8) and (9) are only approximations, it could be necessary to use complex formulae to set fiducial limits to the true mean ovulation time. However, in the present experiment application of the appropriate criterion showed that the approximations are sufficiently close for $(100-\alpha) \%$ fiducial limits to be calculated in the ordinary way as $\hat{x}_{1} \pm u_{\alpha} \sqrt{ }\left[V\left(\hat{x}_{1}\right)\right]$, where $u_{\alpha}$ is the $\alpha \%$ point for the standardized normal variate, i.e. 1.96 for $95 \%$ limits, 2.58 for $99 \%$ limits. Consequently it is enough to present the standard error $\left(\sqrt{ }\left[V\left(\hat{x}_{1}\right)\right]\right)$ for each estimate.

The calculation of the probit regression equations was done on the University of Natal's IBM 1620 computer. 
The above methods involve an assumption that errors in the measurement of heat length are negligible. Unfortunately there can be no assurance of this, but no method of taking such errors into account is known to the authors.

\section{RESULTS}

The calculated equations of types (4), (5) and (6) for each group, with and without the assumption of parallelism are shown in Tables 1, 2 and 3. Only in

TABLE 1

FITTED REGRESSION EQUATIONS FOR $x_{1}$ IGNORING HEAT LENGTH (MODEL 1)

\begin{tabular}{l|c|c}
\hline & Parallel & Non-parallel \\
Treatment & $r=1.4080+0 \cdot 1203 x_{1}$ & $r=0.4843+0 \cdot 1532 x_{1}$ \\
Control & $r=1.9394+0.1203 x_{1}$ & $r=2 \cdot 7054+0.0929 x_{1}$ \\
\hline
\end{tabular}

the case of model (3), is there significant evidence against the hypothesis of parallelism (i.e. in respect of $b_{2}$ ), but, since the addition of the $x_{1} x_{2}$ term is nonsignificant in every case, model (3) does not offer a significant improvement over model (2). On the other hand the addition of $x_{2}$ in model (2) is significant

TABLE 2

FITTED REGRESSION EQUATIONS FOR $x_{1}$ AND $x_{2}$ (MODEL 2)

\begin{tabular}{|c|c|}
\hline $\begin{array}{l}\text { Treatment } \\
\text { Control }\end{array}$ & $\begin{array}{c}\text { Parallel } \\
r=0 \cdot 327119+0 \cdot 191183 x_{1}-0 \cdot 043977 x_{2} \\
r=0.979758+0 \cdot 191183 x_{1}-0.043977 x_{2}\end{array}$ \\
\hline $\begin{array}{l}\text { Treatment } \\
\text { Control }\end{array}$ & $\begin{array}{c}\text { Non-parallel } \\
r=-0.653494+0.246400 x_{1}-0.071448 x_{2} \\
r=\quad 1.924771+0.117317 x_{1}-0.002230 x_{2}\end{array}$ \\
\hline
\end{tabular}

for the treatment group and approaches significance under the hypothesis of parallelism. Thus for the treatment group, but not for the control group, there is a significant correlation between heat length and ovulation time, and model (1) cannot be regarded as an adequate representation of the data. Further, al-

TABLE 3

FITTED REGRESSION EQUATIONS FOR $x_{1}, x_{2}$ AND $x_{1} x_{2}$ (MODEL 3)

\begin{tabular}{|c|c|}
\hline $\begin{array}{l}\text { Treatment } \\
\text { Control }\end{array}$ & $\begin{array}{l}\text { Parallel } \\
r=-0.365843+0.217197 \\
r=\quad \begin{array}{l}x_{1}-0.011536 \\
x_{2}-0.001182\end{array} x_{1} x_{2} \\
\end{array}$ \\
\hline & Non-parallel \\
\hline $\begin{array}{l}\text { Treatment } \\
\text { Control }\end{array}$ & 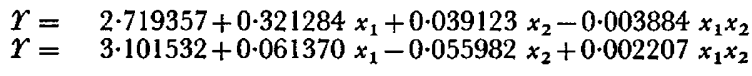 \\
\hline
\end{tabular}


though the differences between the two groups in respect of $b_{1}$ and $b_{2}$ are not significant, the values of $u$ are quite large (1.74 and 1.57 respectively), so that the acceptance of the hypothesis of parallelism is inadvisable.

Since $b_{1}$ in equation (4) is an estimate of the reciprocal of the variance

TABLe 1(a)

MEAN HEAT LENGTH AND MEAN OVULATION TIME (IGNORING HEAT LENGTH) FOR THE TREATMENT AND CONTROL GROUPS CALCULATED FROM THE FITTED REGRESSION EQUATIONS IN TABLE 1

\begin{tabular}{c|c|c|c|c}
\hline \multirow{2}{*}{ Group } & \multirow{2}{*}{$n$} & \multicolumn{2}{|c|}{$\begin{array}{c}\text { Estimated mean ovulation time } \\
\langle\text { hr })\end{array}$} & $\begin{array}{c}\text { Mean heat } \\
\text { length }(h r)\end{array}$ \\
\cline { 3 - 4 } & & Parallel & Non-parallel & \\
\hline Treatment & 100 & $29.9 \pm 1 \cdot 24$ & $29 \cdot 5 \pm 0.94$ & $18 \cdot 9 \pm 0.79$ \\
Control & 100 & $25.4 \pm 1.31$ & $24 \cdot 7 \pm 0.51$ & $25 \cdot 0 \pm 0.86$ \\
\hline
\end{tabular}

of individual ovulation times, it may be observed from Table 1 that the estimated variance of ovulation times is lower for the treatment group than the control, though the difference is not significant. Similarly $b_{1}$ in equation (5) is an estimate of the reciprocal of the variance of ovulation times for a fixed heat length, and from Table 2 we see that this variance is much reduced for the treatment group by taking account of heat length, but reduced very little for

TABLE 2(a)

MEAN OVULATION TIME (MEASURED FROM THE START OF HEAT) AND ESTIMATED PERCENTAGE OF EWES OVULATING BY THE END OF HEAT FOR SELEGTED HEAT LENGTHS CALGULATED FROM FITTED REGRESSION EQUATIONS IN TABLE 2

\begin{tabular}{|c|c|c|c|c|c|c|c|c|}
\hline \multirow{3}{*}{$\begin{array}{c}\text { Heat } \\
\text { length } \\
(\text { hr })\end{array}$} & \multicolumn{4}{|c|}{ Parallel } & \multicolumn{4}{|c|}{ Non-parallel } \\
\hline & \multicolumn{2}{|c|}{ Treatment } & \multicolumn{2}{|c|}{ Control } & \multicolumn{2}{|c|}{ Treatment } & \multicolumn{2}{|c|}{ Control } \\
\hline & $\begin{array}{l}\text { Ovulation } \\
\text { time }\end{array}$ & $\begin{array}{l}\% \\
\text { ovulated }\end{array}$ & $\begin{array}{l}\text { Ovulation } \\
\text { time }\end{array}$ & $\stackrel{\%}{\%}$ & $\begin{array}{l}\text { Ovulation } \\
\text { time }\end{array}$ & $\begin{array}{c}\% \\
\text { ovulated }\end{array}$ & $\begin{array}{c}\text { Ovulation } \\
\text { time }\end{array}$ & $\begin{array}{c}\% \\
\text { ovulated }\end{array}$ \\
\hline $\begin{array}{l}10 \\
15 \\
20 \\
25 \\
30\end{array}$ & $\begin{array}{l}26 \cdot 7 \pm 1.65 \\
27.9 \pm 0.98 \\
29 \cdot 0 \pm 0.57 \\
30 \cdot 2 \pm 0.92 \\
*\end{array}$ & $\begin{array}{c}0 \\
0 \cdot 7 \\
4 \cdot 2 \\
16 \cdot 0 \\
*\end{array}$ & $\begin{array}{c}* \\
24 \cdot 5 \pm 1.96 \\
25 \cdot 6 \pm 1 \cdot 00 \\
26 \cdot 8 \pm 0.96 \\
27 \cdot 9 \pm 0.93\end{array}$ & $\begin{array}{c}* \\
3 \cdot 5 \\
14 \cdot 1 \\
36 \cdot 7 \\
65 \cdot 4\end{array}$ & $\begin{array}{l}25 \cdot 8 \pm 1 \cdot 78 \\
27 \cdot 3 \pm 1 \cdot 12 \\
28 \cdot 7 \pm 0 \cdot 61 \\
30 \cdot 2 \pm 1.07\end{array}$ & $\begin{array}{l}0 \\
0 \cdot 1 \\
1 \cdot 5 \\
10 \cdot 0 \\
*\end{array}$ & $\begin{array}{c}* \\
25 \cdot 9 \pm 3 \cdot 28 \\
25 \cdot 8 \pm 2 \cdot 44 \\
25 \cdot 7 \pm 2 \cdot 13 \\
25 \cdot 6 \pm 1 \cdot 80\end{array}$ & $\begin{array}{c}* \\
10 \cdot 0 \\
24 \cdot 7 \\
45 \cdot 4 \\
69 \cdot 5\end{array}$ \\
\hline
\end{tabular}

* Estimates which would amount to extrapolated values.

the control. This is consequential on the correlation between heat length and ovulation time discussed above. From calculations based on Table 3 there appears to be a tendency for the variance of ovulation times in the treatment group to increase with increasing heat length, while the opposite tendency applies to the control group. In view of the non-significance of $b_{3}$ however, these tendencies are not statistically significant.

Table $1(a)$ gives the estimated over-all mean ovulation time $\left(\hat{x}_{1}\right)$ and the 
estimate of the mean heat length $\left(\bar{x}_{2}\right)$ for the two groups. The latter is $6 \cdot 1 \mathrm{hr}$ less for the treatment group than the control, whereas the former is $4.5 \mathrm{hr}$ greater (assuming parallelism). Both differences are statistically significant.

Tables 2(a) and 3(a) show the estimated mean ovulation times and their standard errors for selected heat lengths. As indicated above, attention may be confined to the estimates obtained in Table 2(a) without the assumption of parallelism. The various estimates obtained under other models show no significant differences from these. In accordance with the significant correlation of heat length and ovulation time for the treatment group, the mean ovulation times for short heats are less than the overall mean for this group ( $29.9 \mathrm{hr})$, but increase with increasing heat length. The gap between end of heat and

TABLE 3(a)

MEAN OVULATION TIME (MEASURED FROM THE START OF HEAT) AND ESTIMATED PERCENTAGE OF EWES OVULATING BY THE END OF HEAT FOR SELECTED HEAT LENGTHS CALGULATED FROM FITTED REGRESSION EQUATIONS IN TABLE 3

\begin{tabular}{|c|c|c|c|c|c|c|c|c|}
\hline \multirow{3}{*}{$\begin{array}{c}\text { Heat } \\
(h r)\end{array}$} & \multicolumn{4}{|c|}{ Parallel } & \multicolumn{4}{|c|}{ Non-parallel } \\
\hline & \multicolumn{2}{|c|}{ Treatment } & \multicolumn{2}{|c|}{ Control } & \multicolumn{2}{|c|}{ Treatment } & \multicolumn{2}{|c|}{ Control } \\
\hline & $\begin{array}{c}\text { Ovulation } \\
\text { time }\end{array}$ & $\begin{array}{l}\% \\
\text { ovulated }\end{array}$ & $\begin{array}{l}\text { Ovulation } \\
\text { time }\end{array}$ & $\begin{array}{c}\% \\
\text { ovulated }\end{array}$ & $\begin{array}{l}\text { Ovulation } \\
\text { time }\end{array}$ & $\begin{array}{c}\% \\
\text { ovulated }\end{array}$ & $\begin{array}{l}\text { Ovulation } \\
\text { time }\end{array}$ & $\begin{array}{c}\% \\
\text { ovulated }\end{array}$ \\
\hline $\begin{array}{l}10 \\
15 \\
20 \\
25 \\
30\end{array}$ & $\begin{array}{l}26 \cdot 0 \pm 0.83 \\
27.2 \pm 0.76 \\
28.5 \pm 0.72 \\
30 \cdot 2 \pm 0.81\end{array}$ & $\begin{array}{c}0 \\
0 \\
0 \cdot 6 \\
12 \cdot 8 \\
*\end{array}$ & $\begin{array}{c}* \\
26 \cdot 4 \pm 1 \cdot 99 \\
26 \cdot 3 \pm 1 \cdot 75 \\
26 \cdot 2 \pm 1 \cdot 92 \\
26 \cdot 1 \pm 2 \cdot 24\end{array}$ & $\begin{array}{c}* \\
9 \cdot 3 \\
25 \cdot 3 \\
29 \cdot 5 \\
66 \cdot 9\end{array}$ & $\begin{array}{l}26 \cdot 7 \pm 1 \cdot 05 \\
27 \cdot 8 \pm 0.82 \\
28 \cdot 9 \pm 0.67 \\
30 \cdot 2 \pm 0.74\end{array}$ & $\begin{array}{c}0 \\
0 \cdot 5 \\
4 \cdot 5 \\
16 \cdot 8 \\
*\end{array}$ & $\begin{array}{c}* \\
24.9 \pm 0.86 \\
25.5 \pm 0.66 \\
26.3 \pm 0.91 \\
27 \cdot 1 \pm 1 \cdot 16\end{array}$ & $\begin{array}{c}* \\
3 \cdot 0 \\
14 \cdot 3 \\
38 \cdot 0 \\
65 \cdot 4\end{array}$ \\
\hline
\end{tabular}

* Estimates which would amount to extrapolated values.

ovulation time is, however, closing all the time as shown by the increasing estimated percentages of ewes ovulating before the end of oestrus. For the control group, time of ovulation is virtually stationary and, of course, there is a decreasing gap between end of heat and ovulation time as heat length increases.

\section{DISCUSSION}

The authors are aware of only one paper in which the ram has been reported to have affected the time of ovulation in the ewe; that of Zeltobrjuh \& Rak (1964). These authors estimated mean time of ovulation for five groups of ewes in which there were different degrees of association between the sexes during oestrus. In two of these groups the treatments applied are comparable to those in the present experiment. Mean oestrous duration and mean ovulation time for these treatments as obtained in the present experiment and by Zeltobrjuh \& Rak are shown diagrammatically in Text-fig. 1. In the group not associated with the ram for the first $24 \mathrm{hr}$ of heat, Zeltobrjuh \& Rak found that ovulation generally occurred some hours before the end of oestrus, while in the comparable group in our experiment mean time of ovulation was found to be shortly after the end of oestrus, except when heat length was $26 \mathrm{hr}$ or greater. 
In such cases ovulation was estimated to occur before the end of oestrus. In the treatment groups (i.e. those mated frequently throughout heat), the results for the two experiments are similar in as much as ovulation occurred after the end of oestrus. However, whereas Zeltobrjuh \& Rak found that mean time of ovulation was earlier when the sexes were associated during oestrus, the results from the present experiment show a significant delay in time of ovulation. The differences recorded may have arisen through the techniques used to estimate mean ovulation time, but it should also be pointed out that since length of heat increases as the season advances (Parsons \& Hunter, 1967), time of ovulation and the effect of the ram may also vary within the season. However, the present findings confirm those of Zeltobrjuh \& Rak that ovulation usually occurs after the end of heat if the sexes are associated during oestrus. They do not conflict with the findings of Anderson (1938), who found that ovulation occurred some hours after the end of a short heat. On the other hand, these results seem to negate the suggestion of Quinlan \& Maré (1931) that the end of heat, and consequently heat length, is dependent upon the rupture of the follicle.

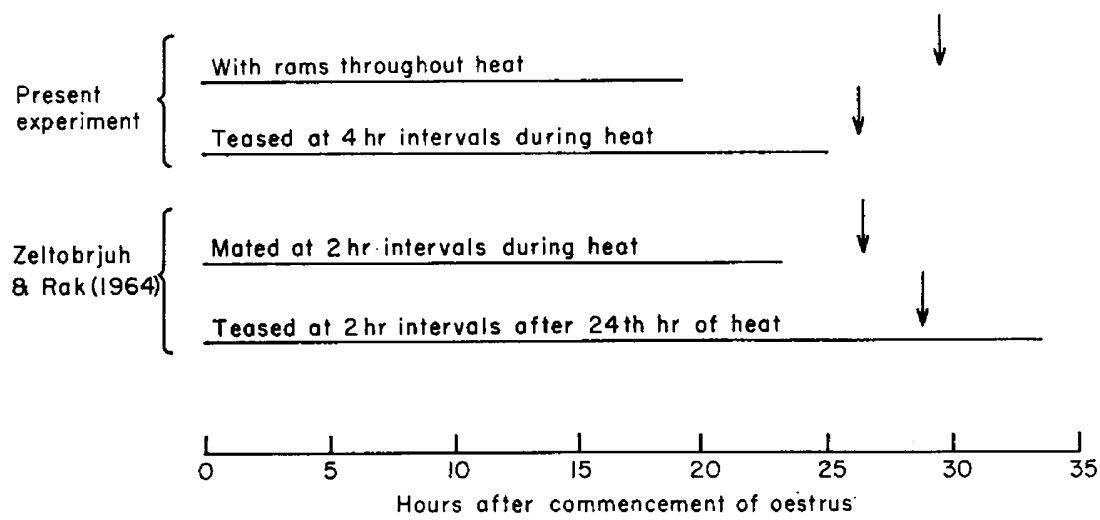

Text-fig. 1. Mean lengths of heat (horizontal lines) and ovulation times (arrows) in ewes.

The stimulus leading to the release of sufficient gonadotrophin to cause ovulation has been shown to occur within $2 \mathrm{hr}$ after the onset of oestrus (Robertson \& Rakha, 1965). This suggests that the influence of the ram on time of ovulation probably occurs within the first $2 \mathrm{hr}$ of oestrus, perhaps by altering the rate of secretion of the luteinizing hormone releasing factor. However, Parsons \& Hunter (1967) have found that rams most effectively shortened oestrus if they were associated with the ewe between 4 and $8 \mathrm{hr}$ after its commencement. This may be a clue to the differences in the mechanisms by which the ram shortens oestrus and delays ovulation.

Restall (1961) suggested that the improved lambing rate achieved by running teaser rams with the ewes after insemination (Lysov \& Simanov, 1955; Restall, 1961 ; Schindler \& Eyal, 1961) might be attributed to the release of oxytocin and improved sperm transportation. It is interesting to speculate that the relationship between heat length and time of ovulation, and perhaps the time necessary for sperm capacitation (Mattner, 1963), might be involved. 


\section{ACKNOWLEDGMENTS}

The experimental animals and the facilities used in these experiments were supplied by the South African Department of Agricultural Technical Services. We are indebted to the staff of the Ukulinga Experiment Station, Pietermaritzburg for care of the animals and to the technical staff and senior students of the Department of Animal Science, University of Natal, for assistance. Grateful acknowledgment is made to Professor D. J. Finney of the University of Edinburgh for his helpful suggestions in respect of the statistical analysis. Thanks are also due to Mr G. L. Webb and Mr R. M. Pringle for assistance in the computation of the data.

\section{REFERENCES}

Allen, E., McKenzie, F. F., Kennedy, J. W. \& Beare, W. K. (1931) Oestrous periods, ovarian changes, and tubal ova in the sheep. Anat. Rec. 48, Suppl. p. 9.

Anderson, J. (1938) Ovulation in the ewe. F. agric. Sci., Camb. 28, 64.

Bischoff, T. L. W. (1844) Beweis der von der Begattung unabhängigen periodischen Reifung und Loslösung der Eier der Saugethiere und des Menschen. Giessen. (Cited by Cole \& Miller, 1935; and by Anderson, 1938).

Burrell, R. J. W., Healy, M. J. R. \& Tanner, J. M. (1961) Age at menarche of South African Bantu schoolgirls living in the Transkei reserve. Hum. Biol. 33, 250.

Cole, H. H. \& MilleR, R. F. (1935) Changes in the reproductive organs of the ewe with some data bearing on their control. Am. F. Anat. 57, 39.

FinNEY, D. J. (1943) The statistical treatment of toxicological data relating to more than one dosage factor. Ann. appl. Biol. 30, 71.

FinNey, D. J. (1944) 'The application of probit analysis to the results of mental tests. Psychometrika, 9, 31.

FinNey, D. J. (1947a) The estimations from individual records of the relationship between dose and quantal response. Biometrika, 34, 320.

FinNEy, D. J. (1947b) The adjustment of biological assay results for variation in concomitant observations. 7. Hyg., Camb. 45, 397.

Finney, D. J. (1962) Probit analysis, 2nd edn. Cambridge University Press.

Grant, R. (1934) Studies on the physiology of reproduction in the ewe. I. The symptoms, periodicity and duration of oestrus. II. Changes in the vagina and cervix. Trans. R. Soc. Edinb. 58, 1.

Ivanow, E. I. (1913) The relation between ovulation and heat in sheep. Preliminary communication, Zootechnical Station, Askania Nova. (Cited by McKenzie \& Terrill, 1937, and Grant, 1934.)

Kelley, R. B. (1937) Studies in fertility of sheep. Bull. Coun. scient. ind. Res., Melb. No. 112.

Lysov, A. M. \& Simanov, J. G. (1955) Methods of increasing fertility in Karakul sheep. Karakulev. Zverov. 8, (2), 9. (Anim. Breed. Abstr. 23, 1759, 1955.)

Marshall, F. H. A. (1904) The oestrous cycle and the formation of the corpus luteum in the sheep. Phil. Trans. R. Soc. B, 196, 47.

MAtTNER, P. E. (1963) Capacitation of ram spermatozoa and penetration of the ovine egg. Nature, Lond. 199, 772.

MaKenzie, F. F. \& Terrill, C. E. (1937) Estrus, ovulation and related phenomena in the ewe. Univ. Mo. agric. Res. Bull. 264.

Parsons, S. D. \& Hunter, G. L. (1967) Effect of the ram on duration of oestrus in the ewe. F. Reprod. Fert. 14, 61.

Quinlan, J. \& MARÉ, G. S. (1931) The physiological changes in the ovary of the Merino sheep in South Africa and their practical application in breeding. 17th Rep. Dir. vet. Serv., Onderstepoort, Un. S. Afr. p. 663.

Restald, B. J. (1961) Further observations on the effect of post-inseminal teasing following artificial insemination in sheep. In: Proc. Conf. on Artificial Breeding of Sheep, p. 87. Ed. E. M. Roberts. University of New South Wales.

Robertson, H. A. \& RakHa, A. M. (1965) The timing of the neural stimulus which leads to ovulation in the sheep. F. Endocr. 32, 383.

Schindler, H. \& Eyal, E. (1961) The effect of post-inseminal teasing on conception. In: Proc. Conf. on Artificial Breeding of Sheep, p. 93. Ed. E. M. Roberts. University of New South Wales.

Wilson, D. C. \& Sutherland, I. (1950) Age at the menarche. Br. med. F. i, 1267.

ZeltobrJuh, N. A. \& RAK, L. P. (1964) Biological stimulation of the reproductive functions of the ewe. Ovcevodstvo, 10 (8), 8. (Anim. Breed. Abstr. 33, 448.) 